inefficacy of current medical regimens in this scenario. In addition, CHB is an autoimmune process that can be associated with damage to the myocardium itself. Thus, an underlying cardiomyopathy affecting cardiac output may play a primary or secondary role in developing hydrops. The impact of fetal inotropic support in our case highlights this point. Our case also illustrates the limitation of altering the pacemaker rate in the postoperative period with current technology. Further, our case demonstrates the limitations of serial weekly fetal echocardiograms and the potential for rather precipitous development of hydrops. Indeed, the findings of chronic multiorgan failure in the postmortem study of our patient highlight the importance of early intervention in these babies, that is, at the very first signs of hydrops.

\section{CONCLUSIONS}

Future research aimed at earlier, noninvasive detection of cardiac failure and organ-system compromise will improve outcomes. Controversial ethical issues and questionable medical indications of open fetal surgery, significant morbidity to the mother, and risks associated to the pregnancy, as well as to future fertility and pregnancies, need to be recognized.

\section{References}

1. Michaelsson M, Engle MA. Congenital complete heart block: an international study of the natural history. Cardiovasc Clin. 1972;4:85-101.

2. Askanase AD, Friedman DM, Copel J, et al. Spectrum and progression of conduction abnormalities in infants born to mothers with anti-SSA/Ro-SSB/La antibodies. Lupus. 2002;11:145-51.

3. Nield LE, Silverman ED, Smallhorn JF, et al. Endocardial fibroelastosis associated with maternal anti-Ro and anti-La antibodies in the absence of atrioventricular block. J Am Coll Cardiol. 2002;40:796-802.

4. Breur JM, Kapusta L, Stoutenbeek P, Visser GH, van den Berg P, Meijboom EJ Isolated congenital atrioventricular block diagnosed in utero: natural history and outcome. J Matern Fetal Neonatal Med. 2008;21:469-76.

5. Kitano Y, Flake AW, Crombleholme TM, Johnson MP, Adzick NS. Open fetal surgery for life-threatening fetal malformations. Semin Perinatol. 1999;23: 448-61.

\title{
Norwood procedure using modified Blalock-Taussig shunt: Beware of the circle of Willis
}

\author{
Selma O. Algra, MD, ${ }^{\mathrm{a}}$ Floris Groenendaal, MD, ${ }^{\mathrm{b}}$ Ton Schouten, MD,${ }^{\mathrm{c}}$ and Felix Haas, MD, ${ }^{\mathrm{d}}$ Utrecht, \\ The Netherlands
}

Neonates undergoing complex cardiac surgery are at high risk of developing cerebral damage. ${ }^{1}$ In the past decades, surgical and cardiopulmonary bypass strategies have been modified to improve neurodevelopmental outcome. One example is the introduction of antegrade cerebral perfusion (ACP) during aortic arch repair, instead of deep hypothermic circulatory arrest. Although it is not yet known whether this indeed is a superior strategy, ACP is now widely used in congenital heart surgery. ${ }^{2}$ This case report shows that when ACP is performed, cerebral near-infrared spectros-

\footnotetext{
From the Department of Pediatric Cardiothoracic Surgery and Intensive Care, ${ }^{\mathrm{a}} \mathrm{De}$ partment of Neonatology, ${ }^{b}$ Department of Pediatric Intensive Care, ${ }^{c}$ and Department of Pediatric Cardiothoracic Surgery, ${ }^{\mathrm{d}}$ University Medical Center Utrecht, The Netherlands.

Disclosures: Authors have nothing to disclose with regard to commercial support.

Received for publication May 25, 2010; accepted for publication June 28, 2010; available ahead of print July 26, 2010.

Address for reprints: Selma O. Algra, MD, Department of Pediatric Cardiothoracic Surgery and Intensive Care, University Medical Center Utrecht, In-house post KG.01.3190, Lundlaan 6, 3584 EA Utrecht, The Netherlands (E-mail: s.o. algra@umcutrecht.nl).

J Thorac Cardiovasc Surg 2011;141:837-9

0022-5223/ $\$ 36.00$

Copyright (c) 2011 by The American Association for Thoracic Surgery

doi:10.1016/j.jtcvs.2010.06.049
}

copy (NIRS) can provide important information about the circle of Willis, which may influence the surgical strategy.

\section{CLINICAL SUMMARY}

A term infant presented with double inlet left ventricle, transposition of the great arteries, and obstruction of the aortic arch. He was scheduled to undergo the Norwood procedure. According to our standard protocol, cerebral magnetic resonance imaging was performed the day before surgery and NIRS electrodes were placed on both sides of the forehead, showing similar values on the right and left hemispheres (mean regional oxygen saturation $76 \%$ on the right and $72 \%$ on the left).

During surgery, a modified Blalock-Taussig (BT) shunt was placed on the brachiocephalic artery, just distal of the bifurcation, to perform ACP $(43 \mathrm{~mL} / \mathrm{kg} / \mathrm{min})$. During this period (50 minutes), right NIRS was continuously $20 \%$ higher than left NIRS (mean right, 92\%; left, 72\%). After arch repair, full cardiopulmonary bypass was resumed and right and left NIRS values approximated each other. However, when the patient was weaned from bypass, asymmetric NIRS values emerged again, but now with lower NIRS values on the right hemisphere. NIRS was monitored until 48 hours 


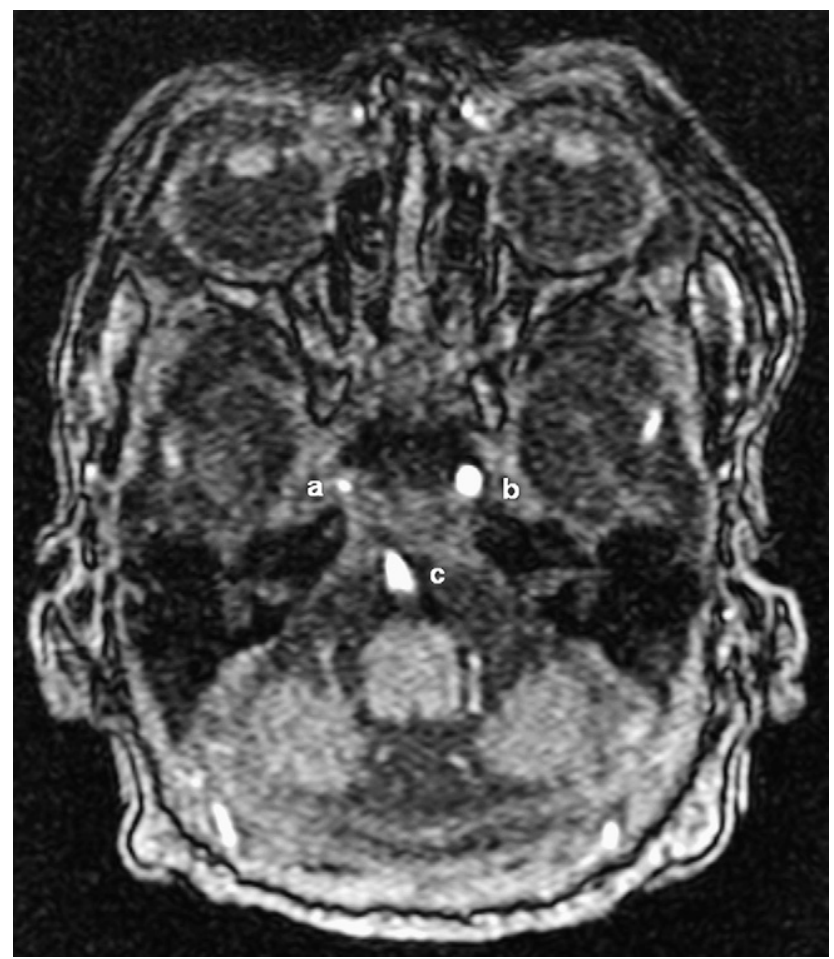

FIGURE 1. Magnetic resonance angiography of the cerebral arteries. A, Right carotid artery. B, Left carotid artery. C, Basilar artery.

postoperatively; right NIRS continued to show a $15 \%$ to $20 \%$ lower value than left NIRS (mean right, $41 \%$; left, 55\%). Continuous electroencephalography showed no abnormalities or asymmetries during the entire perioperative period.

Cerebral magnetic resonance imaging performed 1 week after Norwood palliation showed no ischemic or hemorrhagic lesions. Magnetic resonance angiography revealed that there was no flow through the right carotid artery (preoperatively $71 \mathrm{~mL} / \mathrm{min}$ ), opposed to a flow of $50 \mathrm{~mL} / \mathrm{min}$ and 27 $\mathrm{mL} / \mathrm{min}$ through the left carotid and basilar arteries, respectively. The circle of Willis was incomplete because there was no left posterior communicating artery (Figures 1 and 2).

Three weeks post-surgery, the asymmetry was reassessed by NIRS and ultrasound of the carotid arteries. Both showed no differences between the right and left sides. Neurologic follow-up at 3 and 9 months of age did not reveal any abnormalities.

\section{DISCUSSION}

The modified BT shunt is frequently used for the Norwood stage I procedure. In the literature, it has been suggested that this may result in a reduced flow through the right carotid artery, but this has not been confirmed using modern vascular imaging techniques. ${ }^{3}$ The present case demonstrates a reduced perfusion of the right cerebral hemisphere using multiple modalities.

The reduced flow through the right carotid artery after stage I Norwood is likely due to the combination of a "steal"

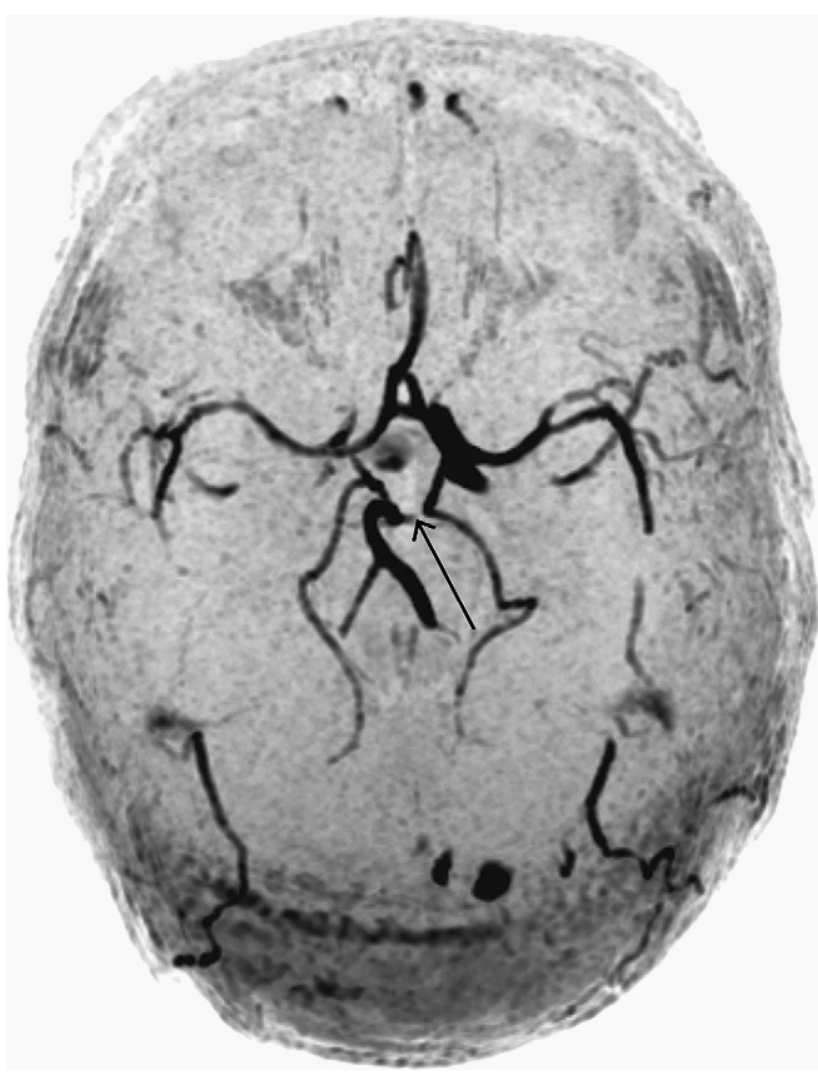

FIGURE 2. Magnetic resonance angiography of circle of Willis. Absent left posterior communicating artery (arrow).

by the BT shunt and a fetal-type (incomplete) variant of the circle of Willis. This occurs in approximately $25 \%$ of the healthy adult population and is even more common in premature neonates. ${ }^{4}$ This need not be a problem if the other (carotid and basilar) arteries are able to compensate. In the present case, the left carotid artery also had perfused the posterior part of the left hemisphere preoperatively. After placement of the BT shunt, perfusion of a major part of the right hemisphere also depended on the left carotid artery. This resulted in a lower perfusion of the right frontal region and subsequently in lower NIRS values on the right. This large strain on the left carotid artery put this child at high risk for cerebral ischemia. Placement of a right ventricle to pulmonary artery shunt may have prevented this situation.

The substantially lower NIRS values on the left hemisphere during ACP were a warning sign of an incomplete circle of Willis in our patient. Asymmetries during ACP in neonatal arch reconstructions have been observed before, however, without vascular imaging studies. ${ }^{5}$

\section{CONCLUSIONS}

A more than $20 \%$ lower left than right cerebral NIRS during ACP is suggestive of an incomplete circle of Willis. In addition, the placement of a modified BT shunt can cause an arrest of flow through the right carotid artery. The 
combination of these 2 is highly undesirable, although this did not have clinical consequences for this patient. Therefore, we propose that when a large asymmetry in NIRS values is noticed during ACP, a right ventricle to pulmonary artery shunt deserves consideration to avoid risk of cerebral damage of the right hemisphere.

\section{References}

1. McQuillen PS, Barkovich AJ, Hamrick SE, Perez M, Ward P, Glidden DV, et al. Temporal and anatomic risk profile of brain injury with neonatal repair of congenital heart defects. Stroke. 2007;38:736-41.
2. Ohye RG, Goldberg CS, Donohue J, Hirsch JC, Gaies M, Jacobs ML, et al. The quest to optimize neurodevelopmental outcomes in neonatal arch reconstruction: the perfusion techniques we use and why we believe in them. J Thorac Cardiovasc Surg. 2009;137:803-6.

3. Kimatian SJ, Myers JL, Johnson SK, Suominen PK. Transcranial Dopplerrevealed retrograde cerebral artery flow during Norwood 1 operation. ASAIO J. 2006;52:608-10.

4. van Kooij BJ, Hendrikse J, Benders MJ, de Vries LS, Groenendaal F. Anatomy of the circle of Willis and blood flow in the brain-feeding vasculature in prematurely born infants. Neonatology. 2010;97:235-41.

5. Andropoulos DB, Diaz LK, Fraser CD Jr, McKenzie ED, Stayer SA. Is bilateral monitoring of cerebral oxygen saturation necessary during neonatal aortic arch reconstruction? Anesth Analg. 2004;98:1267-72.

\title{
Composite reconstruction with cryopreserved fascia lata, single mandibular titanium plate, and polyglactin mesh after redo surgery and radiation therapy for recurrent chest wall liposarcoma
}

\author{
Gaetano Rocco, MD, FRCSEd, Flavio Fazioli, MD, Rocco Cerra, MD, and Rosario Salvi, MD, Naples, Italy
}

Repeated chest wall resections after irradiation often mandate individualized reconstructive strategies. We report a case of a simplified reconstruction with a combination of materials recently used by thoracic surgeons because of their favorable biologic characteristics and user friendliness during implantation.

\section{CLINICAL SUMMARY}

A 68-year-old woman was referred from another institution for a biopsy-proved recurrent G2 liposarcoma of the lower right hemithorax at the level of the eighth to ninth ribs after prior incomplete surgical removal of the myocutaneous layers and subsequent irradiation (70 Gy). Redo surgical intervention was performed by removing en bloc the involved chest wall, making sure to maintain the myocutaneous resection line at $5 \mathrm{~cm}$ from the palpable tumor mass. Reconstruction was done by using a cryopreserved fascia lata homograft anchored to the remaining rib segments. In addition, a single mandibular titanium plate (Synthes, Solothurn, Switzerland) was used to bridge the bony defect (Figure 1, A

From the Department of Thoracic Surgery and Oncology, Division of Thoracic Surgery, Services of Orthopaedic and Plastic Surgery, National Cancer Institute, Pascale Foundation, Naples, Italy.

Disclosures: Authors have nothing to disclose with regard to commercial support. Received for publication May 15, 2010; accepted for publication June 28, 2010; available ahead of print Aug 5, 2010.

Address for reprints: Gaetano Rocco, MD, FRCSEd, Via Terminio 1 Serino (Avel-

lino) 83028 Italy (E-mail: Gaetano.Rocco@btopenworld.com).

J Thorac Cardiovasc Surg 2011;141:839-40

$0022-5223 / \$ 36.00$

Copyright (c) 2011 by The American Association for Thoracic Surgery

doi:10.1016/j.jtcvs.2010.06.050 and $B$ ). The shorter arm of this single plate was fixed with locking screws to the posterior segments of the uninvolved 2 lowermost ribs while the longer arm was anchored to the remaining anterolateral segment of the eighth rib. Given the absence of the overlying muscle and to avoid direct friction of the plate on the approximated skin edges, a polyglactin mesh was sutured to the muscle edges to cover the plate (Figure 1,C). The postoperative course was uneventful, and the patient was discharged home 7 days after the operation. At the 3-month follow-up, the chest radiograph showed a satisfactory outcome (Figure 1, D).

\section{DISCUSSION}

Full-thickness chest wall defects after redo operations and radiation treatment require reconstructive materials warranting structural stability, easy incorporation into the host, and resistance to infection. ${ }^{1,2}$ In this patient, under standard circumstances, a polytetrafluoroethylene patch or a methyl methacrylate sandwich would be used to provide coverage and stabilization with satisfactory results, ${ }^{1}$ although these materials would not be incorporated and remain at risk for subsequent infection. ${ }^{1,2}$ In addition, the interposition of viable myocutaneous flaps would have been necessary to protect the superficial dermocutaneous layers.

The use of titanium plates is gaining popularity for the ability to shape them to fit both in the rib or the sternal position, thereby conferring enhanced stability, and to adapt to the desired geometric configuration. ${ }^{3}$ Recently, several titanium plates were used in conjunction with polytetrafluoroethylene patches in the reconstruction of significant lateral 